\title{
On Ciliary Mechanisms in Brachiopods and some Poly- chætes, with a Comparison of the Ciliary Mechanisms on the Gills of Molluscs, Protochordata, Brachiopods, and Cryptocephalous Polychætes, and an Account of the Endostyle of Crepidula and its Allies.
}

By

\author{
J. H. Orton, B.Sc., A.R.C.Sc.
}

With twelve Figures in the Text.

TABLE OF CONTENTS.

PAGS

Introduction . . . . . . . . . . . . 283

Ciliary mechanisms producing the main food and respiratory current in Brachiopods 284

Ciliary mechanisms on the gill-filaments and lophophore . . . . . . . 287

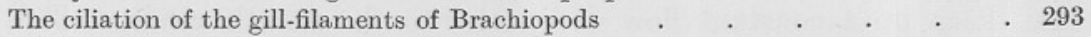

Summary of current-producing mechanisms and the mode of feeding in Brachiopods 294

An explanation of some morphological characters in fossil and recent Brachiopods 295

Comparison of the ciliary mechanisms on the gills of Gastropods, Lamellibranchs,

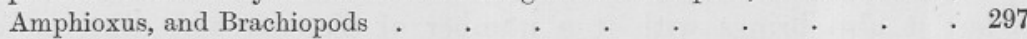

The ciliary mechanisms on the gills of Cryptocephalous Polychætes and on the lophophore of Phoronis . . . . . . . . . . . . 301

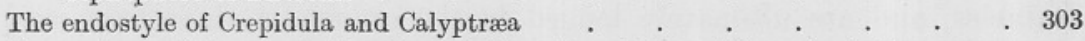

Comparison of the adaptations in Brachiopods and Lamellibranchs to the process

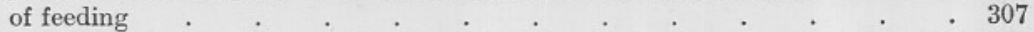

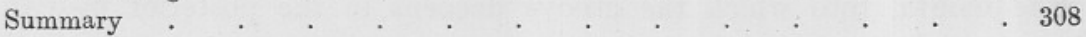

\section{INTRODUCTION.}

THE results of the writer's investigations on the ciliary mechanisms on the gills of Mollusca and Amphioxus (1 and 2) gave rise to the suggestion that similar mechanisms might probably also occur in Brachiopods, for it is a well-known fact that Brachiopods-like some Molluses and Amphioxus-feed on the smaller organisms which are to be found floating in the sea. Owing to the kindness of Dr. H. C. Williamson, of Aberdeen, I have been able to examine living Crania which were obtained by dredging in Loch Fyne, and living Terebratula have also been obtained from Naples. An investigation of the living gill-filaments - or lophophoral cirri, as they are frequently termed in this group-showed that the ciliary 
mechanisms on these filaments are essentially the same as those occurring on the gill-filaments of Amphioxus, Lamellibranchs, some Gastropods, and most Ascidians. As it was found that existing accounts of the mode of feeding in Brachiopods are vague and incomplete the following description of the process has been written.

The nutritive currents in Brachiopods were the subject of an investigation by J. Hérouard (3) as early as 1877 . This writer conceived the ingenious plan of investigating these currents by constructing artificial lophophores of lead piping perforated in places corresponding to the point of attachment of the filaments. It was assumed that a representation of the action of the tentacles would be obtained by squirting water under pressure through the holes in the artificial lophophore. Unfortunately, examination of the living filaments shows at once that this assumption is wrong, and that the experiments consequently were valueless. The gills of Brachiopods have, however, been investigated more recently by Shipley, who described the gill-filaments of Argiope as having cilia on three of their four sides, and figures these cilia as being all similar (see 4, Plate 39, Fig. 13). Later, Shipley (5) states that in Brachiopods " the cilia which clothe the tentacles (i.e. gill-filaments or cirri) keep up a constant flow of water into the mantle cavity. This stream not only serves to aerate the blood of the animals-a process which probably takes place through the thin inner lining of the mantle -but it also brings with it a number of diatoms and other minute organisms which serve as food. These particles become entangled in the tentacles, and are ultimately lodged in the groove at their base, and passing along this by the action of the cilia they find their way into the wide mouth, into which the groove deepens in the posterior median line." It will thus be seen that the manner in which the chief foodcurrent is produced and the differentiation of gill-cilia noted in the following pages have not been described. Moreover, it will be shown here that there exist in various parts of the body other ciliary mechanisms than those on the gill, which play an important part in the process of feeding.

\section{CILIARY MECHANISMS PRODUCING THE MAIN FOOD AND RESPIRATORY CURRENT IN BRACHIOPODS.}

Brachiopods-like Amphioxus, some Molluses, and other animalsobtain their food by maintaining a continuous current of water through a cavity enclosed by portions of the body, and capturing the organisms 
brought along with the current by means of a suitable organ, namely the lophophore, placed between the ingoing and the outgoing currents.

The main food and respiratory stream in Crania enters the mantle cavity at both sides and is expelled in the middle of the front of the shell opposite the hinge (see Fig. 1). It will be remembered that the lophophore in Brachiopods is distributed symmetrically on each side of the antero-frontal axis of the shell. The effect of this disposition is-as will be shown later-to divide the mantle cavity in a physiological sense*

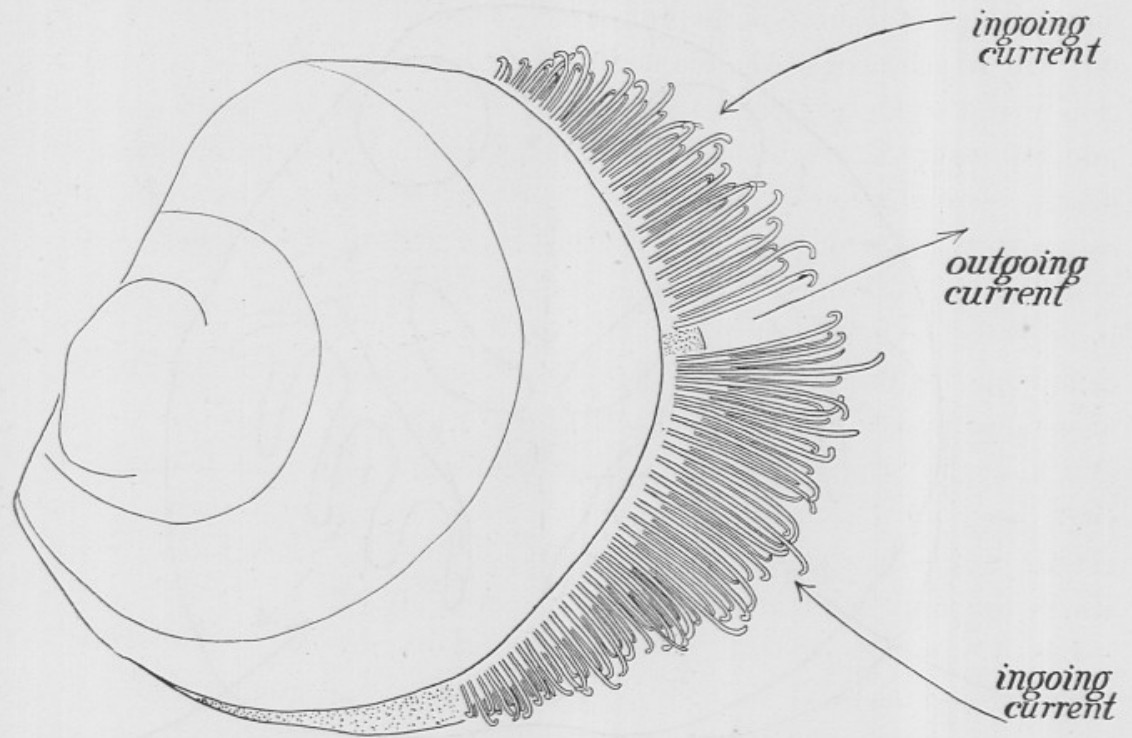

FIg. 1.-View of Crania attached to a stone in the act of feeding. Drawn from the living animal and chiefly from the right side $(\times 10)$. An ingoing current is drawn into the lower portion of the mantle cavity on each side in the antero-lateral region. The outgoing current leaves the region of the shell in the front middle line. The double row of the protruded gill-filaments is well shown.

into two compartments, each containing a half of the lophophore on each side of the mouth. Consequently two inhalent streams are necessary and enter the mantle cavity, as shown in Figs. 1 and 2. The exhalent streams are, however, combined in Crania, Lingula, and probably most recent Brachiopods in the middle line in the front region of the shell.

These main food-currents in Brachiopods are produced chiefly by the lashings of definite rows of cilia situated along the sides of the filaments of the lophophore (see Figs. 3 and 7, pp. 287, 292). Groups of other cilia, however, on other parts of the lophophore and on the mantle

* The mantle cavity is in many genera partially divided also morphologically by septa, viz. Waldheimia, Stringocephalus. (See also p. 295.) 
assist in producing these food-streams. The action of the mantle cilia indicates fairly well the course of the food and respiratory streams through the mantle cavity, and the directions in which the cilia on the lower mantle lash are indicated by the arrows in Fig. 2. From the figure it will be seen that the cilia lash from both lateral regions of the shell towards the front middle region. Besides assisting in producing the main current these cilia also reject from the mantle cavity the heavier undesirable particles brought into the shell in the main stream. On the

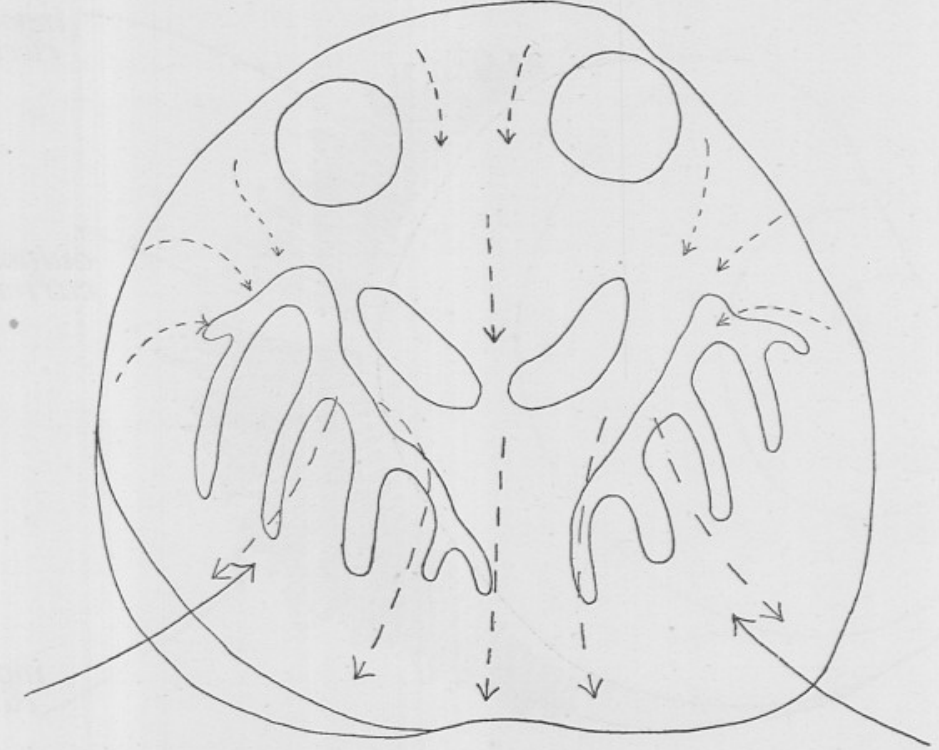

FIG. 2.-View of the ventral valve of Crania, showing the ciliary currents on the mantle ( $\times$ rather more than 3 ).

This view serves almost equally well for the ciliary currents on the dorsal mantle.

The dotted arrows indicate the direction in which the mantle cilia lash, and the large continuous arrows the regions where the greatest volume of the ingoing current enters the mantle cavity.

mantle lining the upper valve the cilia lash on the whole in similar directions to those on the lower one; there are, however, these differences, the cilia on either side of those in the front middle region lash more and more away from the middle the nearer they are situated to the anterior edge of the mantle. Thus two vortices tend to be formed in the right and left upper portions of the mantle cavity. On the dorsal mantle cilia also lash from between the anterior and posterior occlusor muscles on each side towards the posterior sinus of the mantle cavity which constitutes the space bounded by the posterior 
occlusors and the "hinge." Into this sinus opens the anus. An outgoing current from this part of the mantle cavity passes between the anterior occlusors to join the main outgoing stream (see Fig. 2). Thus the currents set up by the mantle cilia on each side of the mantle cavity divide into two streams, the major one passing towards the middle of the cavity and out at the front of the shell in the middle line, and a minor one passing between the occlusor muscles into the posterior sinus, from which the outgoing stream passes between the anterior occlusors to join the major outgoing stream. It will be shown later that the currents set up by the mantle cilia are in the main coincident with those produced by the current-producing cilia on the gill-filaments and certain cilia on the lophophore.

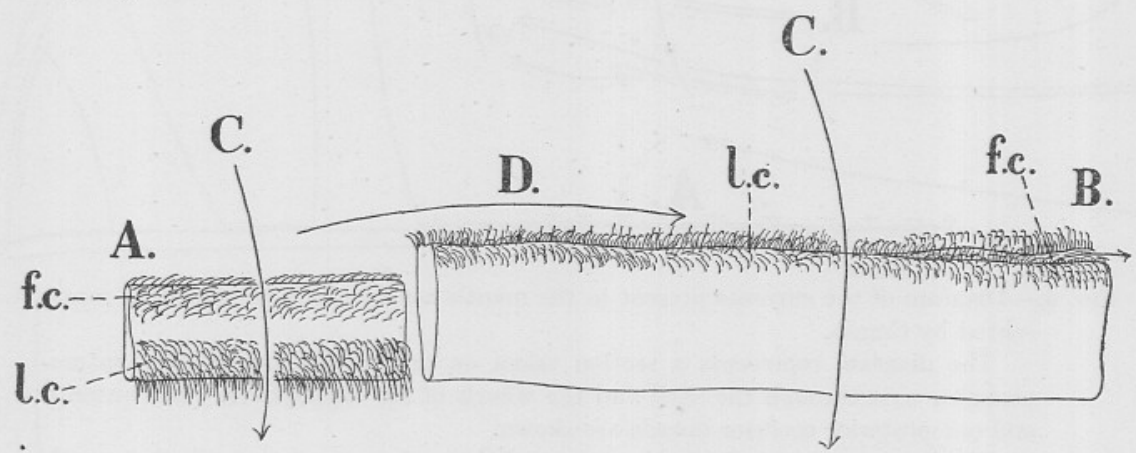

Fig. 3.-Lateral views of living gill-filaments of Crania ( $\times$ about 56).

A. *View of portion of a filament of the ventral series (the letter is placed near the distal end of the filament segment).

B. View of portion of a filament of the dorsal series (the letter is placed near the proximal end of the filament segment).

C. Arrow indicating the direction in which the lateral cilia, l.c., lash.

l.c. Lateral cilia which produce the main current.

D. Arrow indicating the direction in which the frontal cilia, f.c., lash.

f.c. Frontal cilia which collect and transport food-particles.

\section{CILIARY MECHANISMS ON THE GILL-FILAMENTS AND} LOPHOPHORE.

The examination of living gill-filaments of Crania and Terebratula under a high power of a microscope revealed the presence of two sets of cilia $\uparrow$ which correspond in function and position to those on the filaments of Amphioxus, many Molluscs, and most Ascidians. These sets of cilia are well shown in the transverse sections of the filaments

* This view would serve equally well for the tips of both kinds of filaments.

$\dagger$ Blochmann (10) has already figured the differentiation of cilia on the filaments of Crania, without, however, making any observations on their function. 
shown in Fig. 7, p. 292, and in the lateral view of a living filament shown in Fig. 3. From these figures it is seen that the cilia are differentiated into three rows, one extending along that face of the filament which faces the incoming current, and two extending either along the sides of the filaments or along the edges of the filaments at the sides of the former row. Those rows of cilia on the face of the filament facing the incoming current may be called frontal cilia in comparison with the similar cilia

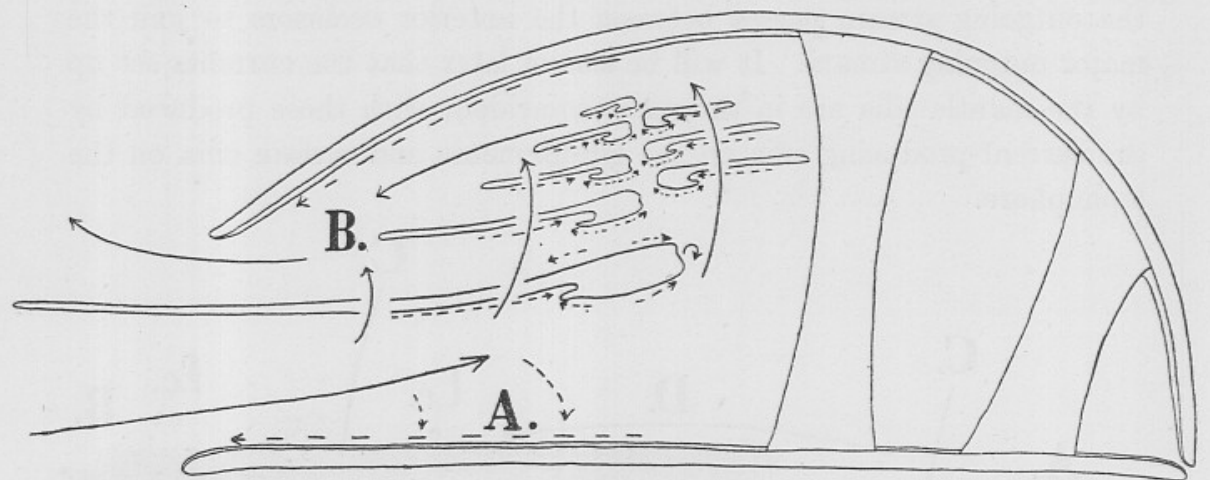

FIc. 4.-Diagram of the currents present in the mantle cavity of a Brachiopod as represented by Crania.

The diagram represents a section taken on one side of the median anteroposterior axis through the shell and the whorls of the lophophore. One anterior and one posterior occlusor muscle are shown.

The larger arrows indicate the course of the main current through the mantle cavity. The large arrow whose head ends above the letter A indicates the course of the ingoing current and the one beginning below $\mathrm{B}$ that of the outgoing current. The three arrows between and to the right of $\mathrm{A}$ and $\mathrm{B}$ indicate the course of the current through the gill-filaments on the lophophore. The dotted arrows on either side of $\mathrm{A}$ indicate the region where the heavier food-particles fall out of the main stream on to the mantle and are expelled by the mantle cilia as indicated by the long dotted arrow placed parallel to the lower mantle. The direction in which the cilia lash on the dorsal mantle is shown by the dotted arrow alongside it. The small dotted arrows on the lophophore and gill-filaments show the course of the food-collecting streams.

A. Inhalent chamber of one side.

B. Exhalent chamber of one side.

described in Molluses and Amphioxus (see 1 and 2), while the rows of cilia on the sides of the filaments may be similarly called lateral cilia. Thus the faces of the filaments may be termed respectively frontal, lateral, and ab-frontal, the latter being the face opposite the frontal. The lateral cilia (well shown in Figs. 3 and 7 l.c.) are the chief producers of the main food and respiratory current in Brachiopods. They lash across the length of the filament, as shown in Fig. 3, from the lower portion of the mantle cavity to the upper. The origin of the lophophore 
from the body is such that the plane of the first and longest turn of the lophophore on each side subtends the antero-lateral angle of the shell.



FIG. 5.-View of a portion of the lophophore, including the buccal groove and the base of five gill-filaments of Crania. Three of the filaments are ventral and two dorsal ones.

(For the sake of convenience the lophophore is magnified less than the gillfilaments. Drawn from the living object.)

The dotted arrows indicate the direction in which the cilia on the body of the lophophore lash, the arrows on the filaments the direction in which the foodcollecting, the frontal cilia lash, and the thin-lined arrows below the buceal lip the direction in which the cilia lash in the buccal groove.

A. Ridge on the lophophore away from which the cilia on both sides lash.

B. Arrows indicating the direction in which the lateral, i.e. current-producing cilia, lash.

B.1. Buccal lip overlying buccal groove.

B.gr. Buccal groove along which are carried the particles from the lophophore.

l.e. Lateral cilia.

f.c. Frontal cilia.

v.f. Filament of ventral series.

a.f. (d.f.) Filament of dorsal series.

Consequently the main current is drawn into the shell at the anterolateral angles, since the lateral cilia lash on the whole in a direction at right angles to the plane of the lophophore. 
When Crania is feeding the gill-filaments are extended in the plane of the lophophore and extruded beyond the opening of the shell, as shown in Fig. 1; they are also usually kept close to the upper valve. This disposition of the filaments permits a selection of the finer foodparticles, for the heavier particles in the ingoing current drop out of the stream at the entrance to the mantle cavity and are rejected by the cilia on the lower mantle as shown in Fig. 2. The main current, however, passes between the filaments on the first turn of the lophophore and onwards through the filaments of the succeeding turns of the spiral lophophore-which are superposed one above the other (see Fig. 4, p. 288)to be passed out of the mantle cavity finally in the anterior middle portion as has been seen. Thus in traversing the mantle cavity the food-stream passes successively through a number of sieves which are formed by the tiers of filaments on the lophophoral spiral. This arrangement is probably very effective in sieving off the food-particles, although at first sight the somewhat straggling appearance of the filaments does not give this impression. The efficiency of the sieving action of the filaments, moreover, is further enhanced by the fact that the filaments are arranged in two distinct alternating rows at the edge of the lophophore (see Fig. 5, p. 289), one row being slightly behind the other, as shown in Fig. 7, which is a transverse section of a group of filaments taken near their origin from the lophophore.* As a result of this disposition the lateral rows of cilia near the base of the upper filaments lash directly on to the frontal face of the lower ones, that is, directly on to the frontal cilia, which are the principal agents in catching food-particles.

An additional minor factor in producing the main food and respiratory stream are the cilia on the body of the lophophore, which have also been figured by Blochmann. These cilia also assist partially in collecting food-particles and their action may best be gathered from Fig. 5, p. 289 and a diagram of a transverse section of the lophophore (see Fig. 6, p. 291). The cilia on the frontal surface of the lophophore are differentiated into two sets separated by a ridge running along the middle of the spiral, but slightly towards the outer, i.e. filamentar side. The cilia on the filamentar side of this ridge are very powerful and lash towards the filaments, those on the other side lash away from the ridge in a direction mainly transverse to the length of the lophophore, but also slightly oblique, towards the proximal end, as shown in Fig. 5, p. 289. The

* The arrangement of the filaments on the lophophore is probably universal in Brachiopods, as it has been observed by Van Bemmelen in Terebratula (6) and Blochmann (10) in Crania, Discina, and Lingula. Oehlert (14) also makes the general statement that they are arranged in two rows in Brachiopods. 
cilia on the ab-frontal face are similar to those on the frontal face (see Fig. 6, below). Thus there are two broad zones of cilia on the filamentar side of both faces of the lophophore lashing towards the filaments and so assisting in producing the food-current, and two zones lashing towards the inner edge of the lophophore, along which particles are carried around the inside of the spiral to its base. At the bases of the two arms of the lophophore the particles carried along the inner edge of the lophophore are passed on to the lower mantle, whence they are expelled from the mantle cavity.

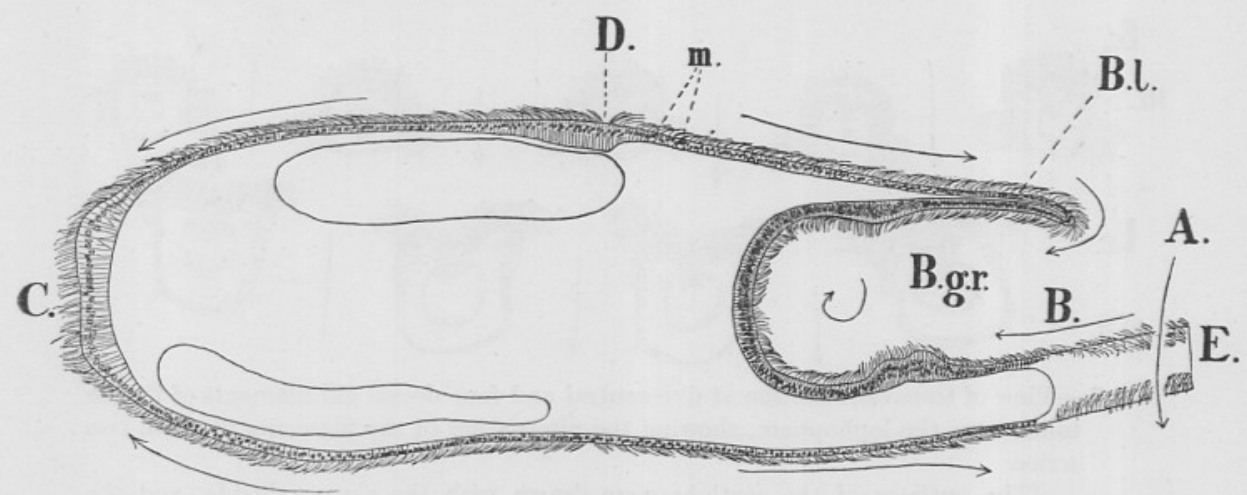

Frg. 6.-Semi-diagrammatic transverse section of the lophophore of Crania to show the difference in the action of the cilia on its various parts as indicated by the adjoining arrows.

A. Arrow indicating the direction in which the current-producing cilia lash on the portion of the gill-filament $\mathrm{E}$.

B. Arrow indicating the direction in which the frontal cilia on the gillfilament lash.

B.gr. Buccal groove along which food is carried to the mouth.

B.1. Buccal lip.

C. Inner edge of lophophore along which particles are carried to its base.

D. Region from either side of which the cilia lash in opposite directions, resembling a watershed.

E. Base of a gill-filament arising from the lophophore.

m. Mucus globules.

It will now be seen that there are three factors concerned in the production of the main food and respiratory stream in Crania - and probably in most, if not all, Brachiopods-namely, the rows of lateral cilia on the gill-filaments, which are the most important factor, the cilia on the filamentar sides of the body of the lophophore, and the cilia on the mantle lobes.

Food-collection in Brachiopods is effected chiefly by the frontal cilia on the gill-filaments, and partially by the cilia on the frontal face of the outer side of the body of the lophophore. The cilia on the frontal face 
of the filaments collect food-particles and lash them towards the base of the filaments into the food groove (see Fig. 5, p. 289). In the same way the frontal cilia on that part of the lophophore adjacent to the food groove entrap food-particles and lash them along the face of the lophophore either on to the base of the filaments or towards the powerful cilia at the edge of the buccal lip (see Fig. 5). These cilia quickly push the particles under the lip into the food groove. The food-particles, on entering the food groove, are then carried along towards the mouth, as has been stated by Shipley, being rapidly transported thence by very

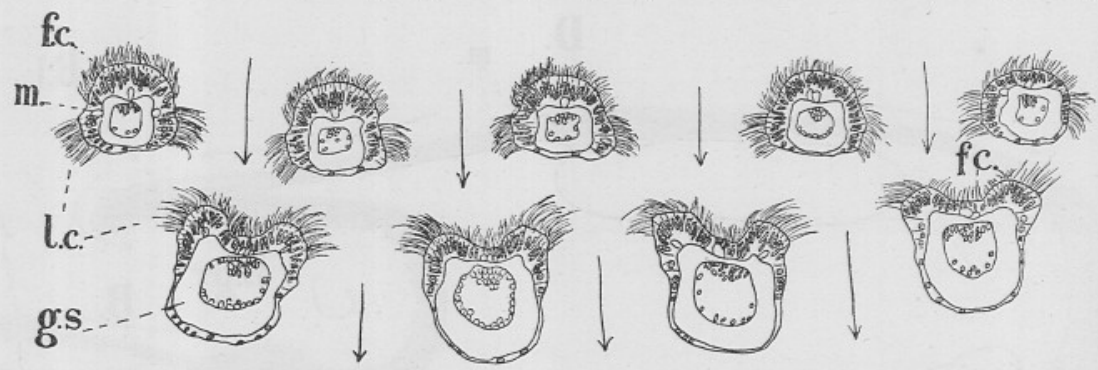

FIG. 7.-View of transverse section of five ventral and four dorsal gill-filaments of Crania taken near the lophophore, showing the alternation of the filaments in these two series.

(The outlines of the sections were drawn with the camera lucida, and the remainder filled in slightly diagrammatically $(x$ about 192.)

The arrows indicate the directions in which the lateral cilia lash, and it will be seen that those of the smaller ventral filaments lash directly on to the frontal surface of the larger dorsal filaments.

l.c. Lateral cilia which lash across the length of the filament, as indicated by the arrows, to produce the main current.

f.c. Frontal cilia, which lash along the length of the filament and collect and transport food particles.

m. Globules of mucus seen in all the sections on various parts of the frontal and lateral sides of the filamentar epithelium.

g.s. The gill-filament supports.

strong cilia. In the process of food-collection the secretion and transportation of mucus plays an important part, for the mucus when spread out in thin layers forms an efficient method of capturing and retaining. captured food-particles, and is also easily transported in this form by cilia. Mucus serving this purpose is secreted by the frontal epithelium on the gill-filaments and especially by that of the dorsal filaments, where. the secreting cells occur chiefly in the trough of the filamentar groove. (see Fig. 7, above, and also Van Bemmelen, 6, Taf. 8, Fig. 6, in a section of a gill-filament of Rhynchonella psittacea). Blochmann (10) has. described aggregations of mucus cells between the bases of the filaments, that is, in the buccal groove, and also others scattered over the epithelium 
of the lophophore. The secretions of these latter cells assist in a similar way to that from the filaments in the capture and transportation of food-particles.

\section{THE CILIATION OF THE GILL-FILAMENTS OF BRACHIOPODS.}

The cilia on the gill-filaments of Brachiopods are arranged in three rows along the length of the filament, as has already been described. There are, however, as Oehlert has observed, two kinds of filaments, a larger and a smaller, as is shown in Fig. 7, p. 292. The smaller ones constitute the ventral series (that is, the series facing the incoming current) on the lophophore and alternate with the larger ones in the dorsal series (see Fig. 5, p. 289). These two kinds also differ in the arrangement of the rows of cilia. On the smaller ones the lateral cilia are situated on the sides of the filaments and near the ab-frontal face, while in the larger filaments they occur similarly on the sides, but near the frontal face, except towards the tips of the filaments, where these current-producing cilia graduate towards the ab-frontal face (see Fig. 3, p. 287). The disposition of the rows of cilia is well shown in Fig. 7, p. 292, which represents transverse sections of the two kinds of filaments taken near their origin from the lophophore. In the smaller sections the filaments are shown to be nearly cylindrical and the greater part of the convex face occupied by the frontal, that is, food-collecting cilia. The larger cilia on the sides of the filaments are the lateral or current-producing cilia. Both these rows of cilia arise from columnar cells which have long elliptical nuclei. On the contrary the non-ciliated ab-frontal epithelium is composed of squarish to flattened cells with more or less spherical nuclei, and indeed it would appear that the character of an epithelium on any gill-filament forms a very good guide as to whether or not that epithelium is ciliated; if the cells in a portion of an epithelium are columnar and the nuclei elongated they probably bear cilia, whereas if the cells are squarish to squamous they are probably not ciliated. Such an interpretation of portions of an epithelium on gill-filaments may be useful in cases where it is difficult to obtain well-preserved material, for as is well known it is difficult to determine what part of an epithelium is ciliated unless such material can be obtained. One good illustration of this fact is afforded by the well-drawn figure of a transverse section of a gill-filament of Rhynchonella given by Van Bemmelen (6, Plate 8, Fig. 6). In this figure no cilia are shown at all, although the characters of the epithelium are seen to be almost identical with that of the smaller sections in Fig. 7, p. 292. A somewhat diagrammatic transverse section 
of a filament of Argiope is figured by Shipley (4), who depicts uniform cilia on three of the four sides of the filament. Examination of the living filaments* and sections of specially preserved material, however, would doubtless show that a differentiation of cilia occurs here as on the filaments of Crania, Rhynchonella, Terebratula, and other forms. Blochmann, however, has given beautiful figures of transverse sections of the gillfilaments of Crania, in which the differentiation of the lateral and frontal cilia is very well shown in a section of a filament of the dorsal series, but less well in that of a ventral filament. This writer also gives rougher figures of Discina and Lingula, without, however, figuring the cilia, but he remarks that the filaments of these two forms are essentially similar in their characters to those of Crania. Hence there can be no doubt that the gill-filaments of all Brachiopods have cilia disposed and differentiated in the same way as in Crania.

\section{SUMMARY OF CURRENT-PRODUCING MECHANISMS AND THE MODE OF FEEDING IN BRACHIOPODS.}

The main current through the mantle cavity in Brachiopods is produced chiefly by the lateral cilia on the gill-filaments and partially by cilia on the mantle and on the body of the lophophore. The disposition of the lophophore and the filaments on the lophophore is such that two ingoing currents of water are established at the sides of the mantle cavity. On each side the current passes between the filaments of the first turn of the lophophore and outwards through the filaments of the second and succeeding turns of the lophophoral spiral into the median dorsal region of the mantle cavity. At this point the currents from each side meet and pass out of the mantle cavity at the middle of the anterior region of the shell.

The food-particles brought into the mantle cavity in the main stream are caught by the frontal cilia on the gill-filaments, and by those on the outer frontal portion of the lophophore, and transported by these cilia into the buccal groove. In the buccal groove the food-particles are lashed rapidly along to the mouth by the strong cilia on the buccal lip and fused bases of the filaments. It seems probable that the food-stream in Brachiopods is effectively sieved by the gill-filaments, since besides collecting food-particles the ventral ones lash directly on to the food-collecting face of the lower filaments which alternate with them : moreover, part of the food-stream is repeatedly sieved in most forms by the filaments on the superposed whorls of the lophophore.

* Subsequent examination of living Argiope from Naples has shown this statement to be correct. 
In Crania a selection of the finer food-particles is effected in the following manner : the ingoing currents are drawn into the dorsal portion of the mantle cavity, hence when the dorsal valve is uppermost-as frequently happens - the heavier particles drop on to the ventral mantle, whose cilia discharges them either outside the mantle cavity or carries them to the edge of the mantle, whence they are shot away by the animal suddenly clapping together the valves of the shell. Modifications in the manner of rejecting unsuitable food-particles probably occur in other Brachiopods in much the same way as has been observed in Lamellibranchs (1, pp. 457 to 463$)$.

\section{AN EXPLANATION OF SOME MORPHOLOGICAL CHARACTERS IN FOSSIL AND RECENT BRACHIOPODS.}

In the foregoing description it has been shown that in certain Brachiopods, as, for example, Crania, there is a physiological subdivision of the main part of the mantle cavity into right and left portions, and it would seem highly probable that in all Brachiopods there is a similar subdivision of the mantle spaces, since the disposition of the lophophore is fundamentally similar in them all. Unfortunately few observations have been made on the nutritive currents of Brachiopods, but those of Morse on Lingula (7, p. 157) are of interest. Morse found that Lingula lives embedded in sand, and that "while partially buried in the sand the anterior border of the pallial membranes contract in such a way as to leave three large oval openings, one in the centre and one on each side. The bristles, which are quite long in this region of the animal, arrange themselves in such a way as to continue these openings into funnels and entangle the mucus which escapes from the animal ; these funnels have firm walls. A continual current is seen passing down the side funnels and escaping by the central one."* These observations have been confirmed by François (8) in so far as he figures the trilobed apertures of the burrows of this animal (see also Camb. Nat. Hist., Vol. 3, Fig. 321). Thus there can be little doubt that the mantle cavity is subdivided in Lingula in the same way as in Crania.

In these respects it is a highly interesting fact that many Brachiopods both recent and fossil have a trilobed shell whose apertures correspond to the inlets for ingoing currents and the outlet for the outgoing current (see Fig. 8 C, p. 296), but it is probably still more interesting and remarkable that in some forms, as in Conchidium Knighti, the mantle cavity is

* The italics are mine. 
practically subdivided into right and left portions by a median septum, and that in others, as in Terebratula janitor, the shell is actually divided into two wings (see Fig. $8 \mathrm{~A}$ and $\mathrm{B}$, below). In all Brachiopods there would thus appear to be little doubt of the physiological independence of the right and left halves of the mantle cavity. Hence variations in the direction of formation of antero-posterior median septa, as shown in Stringocephalus, Conchidium, and many other genera, of trilobation of the shell, as shown in many Rhynchonellidæ, and bilobation of the shell, as shown in Orthis biloba, Terebratula diphya, and other forms, do not interfere with the functions of the two portions of the lophophore, and it is con-
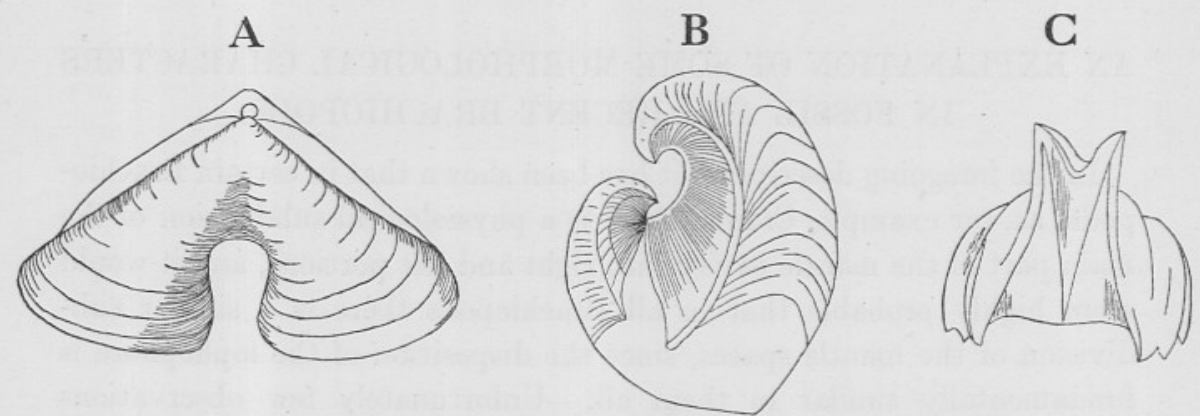

Fic. 8.-Views of types of Brachiopod shells showing morphological division of the mantle cavity into right and left portions, and trilobation of the shell.

A. Shell of Terebratula (Pygope) janitor (after Oehlert) in which the mantle cavity is almost entirely divided into two separate compartments.

B. View of interior of shell of Conchidium Knighti (after Davidson) showing internal partial subdivision of the mantle cavity by the septa which are shaded.

C. Frontal view of the shell of Rhynchonella cynocephala (after Oehlert), showing the anterior median portion of the shell produced into a sort of siphon in the region in which in other Brachiopods (for example, Crania and Lingula) is expelled the outgoing current.

ceivable that these variations may be advantageous to certain forms under certain conditions.

The disposition of the lophophore in the Spiriferidæ indicates that the main ingoing current entered the mantle cavity in the front middle portion and was expelled in two outgoing currents at the postero-lateral angles of the shell, a condition exactly the reverse of that obtaining in Crania, where the ingoing current is twofold and the outgoing current single. Thus the production of the shell-frequently occurring in this group-into postero-lateral angles, somewhat like those occurring in modern Pectens, may have served as a sort of siphon for carrying away the exhalent streams. 


\section{COMPARISON OF THE CILIARY MECHANISMS ON THE GILLS OF GASTROPODS, LAMELLIBRANCHS, AMPHIOXUS, AND BRACHIOPODS.}

The ciliary mechanisms concerned in producing the main food and respiratory current in Gastropods, Lamellibranchs, Amphioxus, Ascidians, and Brachiopods have now been shown to be essentially similar in all these groups (see preceding pages and Orton, $1^{*}$ and 2 , and Herdman, 9). The main current is produced in all groups alike chiefly or entirely by the rows of cilia, the lateral cilia situated at the sides of the gill-filaments (see Fig. 9, p. 299) : for the term " gill-filament" may be used as well for the gill-bars of Amphioxus or Ascidians and the lophophoral cirri of Brachiopods as for the elements of the ctenidium of Gastropods and Lamellibranchs. These rows of lateral cilia lash across the length of the gill-filaments in all cases and set up a current towards and at right angles to the gill. The current thus produced brings into the mantle cavity —or the branchial sac in the case of the Protochordatafood-particles, which serve for the nourishment of the animal, and also brings the means for oxydation of the tissues, while the expulsion of the current from within the cavities of the animals serves to carry away the waste products resulting from the various activities of the organisms.

The food-particles carried in the main current into the spaces of all these animals are arrested on the gill which is necessarily interposed between the ingoing and outgoing currents, and acts like a sieve. The actual collection of food-particles varies somewhat in the different groups. Food-collection is effected chiefly, however, in all the groups by means of rows of cilia on those faces of the filaments facing the oncoming current, that is, on the frontal faces. In some Lamellibranchswhich are curiously distributed throughout the group, as Nucula, Solenomya, Anomia, Mytilus, Cardium, Ostrea, Tapes-there are additional food-collecting cilia on the latero-frontal edges of the gill-filaments. These latero-frontal cilia are true straining cilia, and lash across the length of the filament at right angles to the oncoming current and away from the inter-filamentar spaces. In this way they pass particles on to the frontal cilia, and indeed are so numerous in these animals as to give

* In a paper written in 1910 Bourne (11) states of the lateral eilia of the Gastropod Incisura (Scissurella) lytteltonensis that he does not think "that their function is to hold the filaments together, but simply to create currents over the surfaces of the filaments." I hasten to give this reference because I only became aware of it after my paper on the ciliary mechanisms in Gastropods was published. From the researches described in that paper it is now seen that there is an element of truth in the suggestion made by Bourne. 
the appearance of flexible combs working along the sides of the filaments. The frontal cilia in all forms lash the food-particles into a food-groove, whence the particles are carried to the mouth or œsophagus. It is an interesting fact that the frontal cilia are in all cases short, as compared with the length of the lateral or the latero-frontal cilia, and it is probable that short cilia would be much more effective than long ones in transporting food-particles and masses of particles embedded in mucus, and would, moreover, be more easily controlled and less liable to become intermixed and so interfere with their fellows.

Food-collection is also assisted in some Gastropods as in Crepidula, and some Lamellibranchs as in Nucula, by rows of cilia on the ab-frontal faces of the filaments, but probably the function of these rows of cilia in assisting in producing the main current is more important than that of food-collecting. In Amphioxus and Ascidians cilia on the epithelium of the atrial cavity help in a small way in producing the main stream.

The distribution of the cilia on the gill-filaments of Gastropods, Lamellibranchs, Amphioxus, and Brachiopods is shown in the transverse sections depicted in Fig. 9, p. 299. From these figures the essential similarity of all the filaments is at once apparent. The position of the lateral cilia is, however, somewhat different in the types of filament represented by those of Crepidula and Crania. In those filaments the lateral cilia occupy a position much nearer the ab-frontal surface of the filament. It is probably significant that in both Crepidula and Crania the gill-filaments are free and without any extensive interlocking arrangements such as exist in Lamellibranchs, or such a consolidation as occurs in Amphioxus and Ascidians. It is very probable therefore that the receding of the lateral cilia from the frontal surface in these forms is an effort to compensate for the lack of compactness in the gill, by exposing a larger food-collecting, that is, frontal surface.

A glance again at Fig. 9 shows that in all these filaments internal supports (g.s.) are developed similarly, but with some differences in order to maintain the gills sufficiently rigid in the form of either an open basketwork or grid-iron sieve.

In an earlier paper (2) it has been suggested that the function of the gill in Crepidula, most Lamellibranchs and Amphioxus is merely that of a water-pump and a food-sieve, and that the respiratory function is not performed to any appreciable extent on the gill in these forms. In Brachiopods, Shipley $(4$, p. 501) has arrived at the same conclusion with regard to the function of the lophophore, of which he states: "I have been unable to detect any blood corpuscles in the tentacles, and I believe 


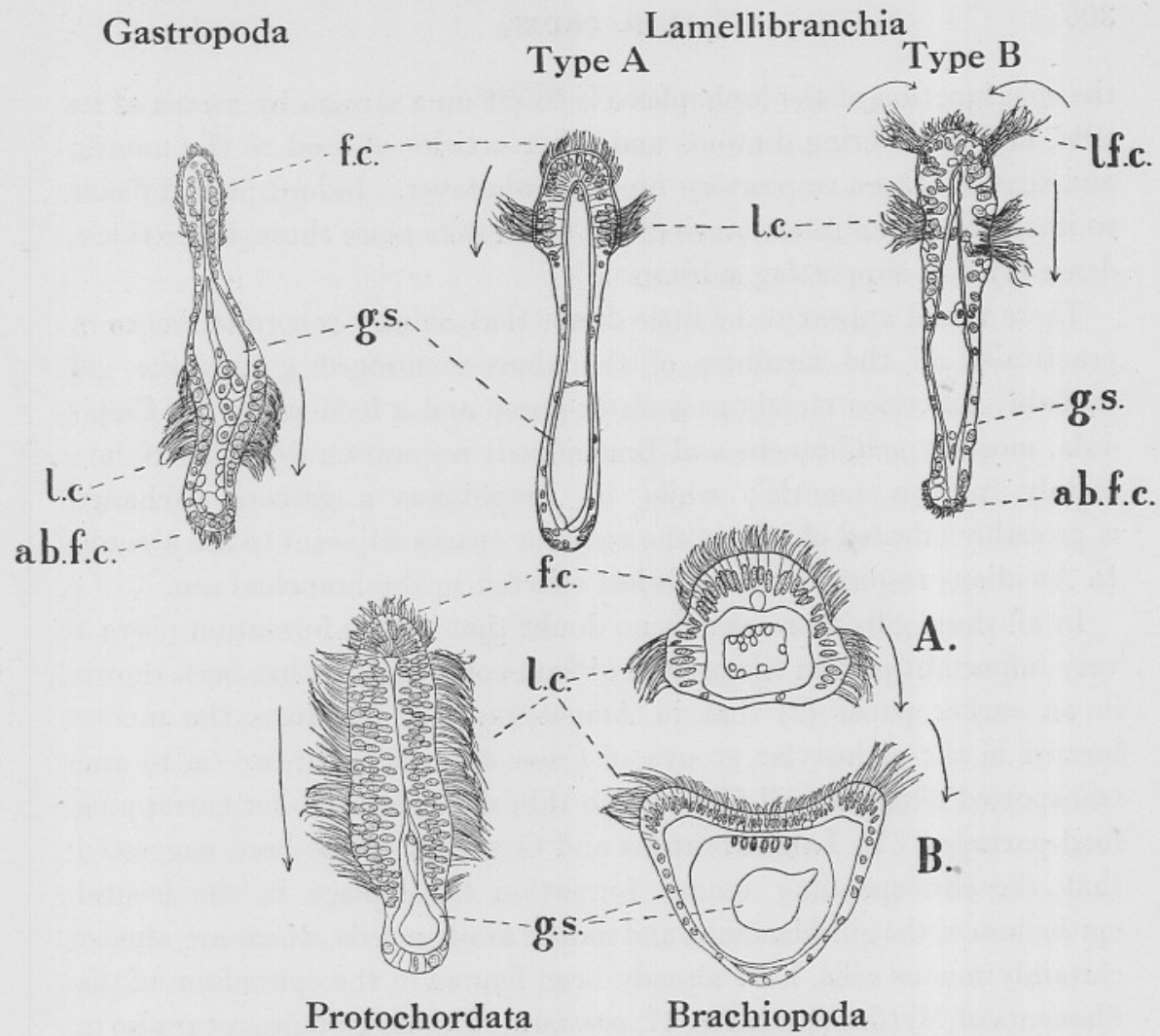

FIG. 9.-Transverse sections of the gill-filaments of members of Gastropods, Lamellibranchs, Protochordata, and Brachiopods, illustrating the essential similarity of the ciliation of the filaments in all these groups. (Variously magnified.)

l.c. Lateral cilia which produce the main food and respiratory current in all the groups.

f.c. Frontal cilia which are the main food-collecting cilia in all the groups.

l.f.c. Latero-frontal cilia, which are special food-catching cilia present only in some Lamellibranchs, as Nucula, Anomia, Mytilus, Cardium, and others; they lash in the direction shown by the adjoining arrows.

ab.f.c. Ab-frontal cilia present and well developed in Gastropods and some Lamellibranchs, but less well developed in Amphioxus and Ascidians; absent in Brachiopods. These cilia assist both in food-collection and in producing the main current.

g.s.

Internal supports for the gill-filaments and present in all the groups, but additional support by calcareous spicules is given in some Brachiopods, as in Terebratula vitrea, shown in the Brachiopod section B.

In the above types of gill-filaments Gastropods are represented by a transverse section of a filament of Crepidula fornicata; Lamellibranchs by two sections representing the two types of ciliation in this group. Type A is of Glycimeris glycimeris, and would serve equally well for Pecten, Arca, and others. Type B is of Mytilus edulis, and represents Nucula, Solenomya, Anomia. Cardium, Ostrea, Anodon, and many others. Protochordata are represented by a section of a secondary gillfilament of Amphioxus lanceolatus, but sections of Ascidian and Enteropneustan (as represented by Ptychodera) gill-filaments are essentially similar to that of Amphioxus in their ciliation.

The two kinds of filaments present in Brachiopods are represented by the Brachiopod sections A and B. The section A is of a ventral filament of Crania anomala, and $\mathrm{B}$ is of a dorsal filament of Terebratula vitrea. The latter section is slightly idealized in that the supporting spicules present within the chitinous gillsupport are represented in the drawing although dissolved out of the actual section by the fixative. 
the sole function of the lophophore is to set up a stream by means of its cilia, and so to bring diatoms and other articles of food to the mouth, and that it has no respiratory function whatever. Indeed, it is difficult to imagine how an interchange of gas could take place through the thick, dense layer of supporting substance."

There would appear to be little doubt that Shipley is correct, hence in practically all the members of the above-mentioned groups the gill probably functions merely as a water-pump and a food-sieve. In Crepidula, most Lamellibranchs and Brachiopods respiration doubtless occurs mainly in the mantle; while in Amphioxus a gaseous exchange is probably effected chiefly in the colomic spaces adjacent to the atrium. In Ascidians respiration is doubtless effected in the branchial sac.

In all these gills there can be no doubt that mucus formation plays a very important part in the process of food-collection. It has been shown in an earlier paper (2) that in Amphioxus and Ascidians the mucus formed in the endostylar groove of these animals is thrown on to and transported along the gill-filaments in thin sheets to serve for entrapping food-particles. In Lamellibranchs and Crepidula it has been suggested that the corresponding mucus formation takes place in the frontal epithelium of the gill-filaments, and indeed swollen cells, which are almost certainly mucus cells, have already been figured in the epithelium of the filaments of Mytilus (see I, Fig. 17, passim). Similar globules occur also in the filaments of Glycimeris, Crania (see Fig. 9, p. 299), Terebratula and Rhynchonella (see 6). It is hoped to make this important problem the subject of a special investigation.

The writer's work, however, on the endostyle of Amphioxus suggested the probable function of a previously enigmatical glandular organ situated along the base of the gill-filaments of Crepidula. An examination of the living animal confirmed the suggestion that this organ is indeed an endostyle, as may be gathered from the description of it in the section on p. 303 .

It is an interesting fact that the spines (clavulæ) composing the fascioles of the heart-urchins, Echinocardium and Spatangus, have been found to have the cilia disposed in definite rows along their sides in a manner very similar to that in which the lateral cilia are distributed on the gill-filaments of all the above-mentioned groups. These rows of cilia on the spines do, as a matter of fact, very closely resemble the lateral cilia of gill-filaments in that they lash in a definite direction and with the same wave-like motion characteristic of those current-producing cilia ; they are also situated on opposite sides of the spines, and are indeed 
current-producing cilia analogous to those of Gastropods, Lamellibranchs, Ascidians, Amphioxus, and Brachiopods.

The function of these spines is being investigated further, and figures will be given to show their resemblance to gill-filaments. MacBride, however, is doubtless correct in stating (Camb. Nat. Hist., Vol. I, p. 550) that : "Between the two posterior petals (in Echinocardium cordatum) there is a hoop-shaped band of very small black spines. These spines are ciliated, and draw a current of fresh sea-water over the respiratory tube-feet. Beneath the periproct there is a similar band called the 'sub-anal fasciole'; this probably produces a current of water which sweeps away the material ejected from the anus."

\section{THE CILIARY MECHANISMS ON THE GILLS OF CRYPTO- CEPHALOUS POLYCHATES AND ON THE LOPHOPHORE OF PHORONIS.}

An examination has also been made of the cephalic gills of various Cryptocephalous Polychætes. It has been found that these gills are used for the purpose of feeding, and that the ciliary mechanisms concerned in the feeding process in-for example-Spirorbis, Pomatoceros, Hydroides, Branchiomma, Sabella, and Filograna are identical with those on the gills of Lamellibranchs, some Gastropods, Amphioxus and Brachiopods, that is to say, there are well-differentiated current-producing lateral cilia and food-collecting and food-transporting frontal cilia on the pinnules of the tentacles. Food is very rapidly collected in these Polychætes and transported along the pinnules to the axes of the tentacles and thence to the mouth. Further particulars and figures with regard to these animals will, however, be given later.

The lophophoral cirri of Phoronis have also been investigated, but up to the present it has only been possible to examine the living animal cursorily. Nevertheless this short examination revealed the facts that in this animal also the cirri-or gill-filaments-are differentiated into lateral and frontal rows, and that a good current of water is drawn towards the mouth within the space enclosed by the lophophoral cirri. The functions of the lateral and frontal cilia in Phoronis, however, do not appear to be identical with those of the similar cilia in Brachiopods and the other groups mentioned above, but a more complete examination of the living animal will be made later with a view to investigating fully the ciliary mechanisms concerned in process of feeding in this animal. 


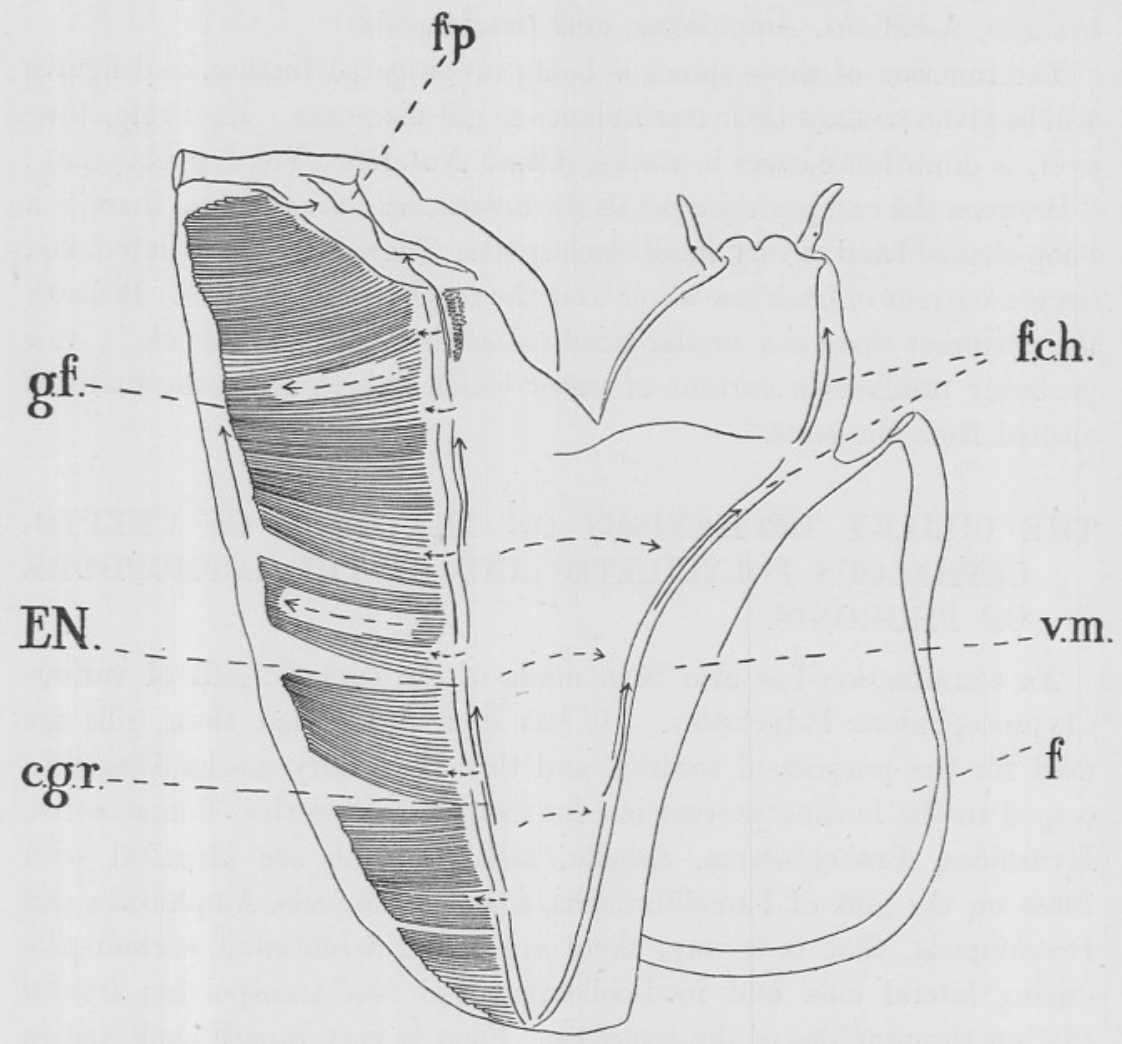

Fig. 10.-View of the mantle cavity and gill of Crepidula, showing the endostyle at the base of the gill. (The animal has been taken out of its shell and the mantle turned over to the left.)

The dotted arrows on the endostyle, En, indicate the directions in which mucus is lashed from the endostyle on to the base of the gill-filaments.

EN. Endostyle from which mucus and food-particles are lashed on to the gill-filaments.

c.gr. Ciliated groove along the left side of the endostyle carrying mucus forwards to the food-pouch, as indicated by the complete arrows.

f.p. Food-pouch in which the heavier food-particles become lodged.

f.ch. Food-channel on the right side of the body extending along the visceral mass and the "neck" region of the animal towards the mouth. In this channel is collected the main mass of collected food-particles which are carried in the direction indicated by the arrows.

f. Foot.

v.m. Visceral mass.

g.f. Gill-filaments. 


\section{THE ENDOSTYLE OF CREPIDULA AND CALYPTRAA.}

At the base of the gill-filaments of Crepidula and Calyptræa there is a group - or rather there are two groups-of large glandular ciliated cells which secrete a mucoid substance (see Figs. 10 and 12,p. 304). Examination

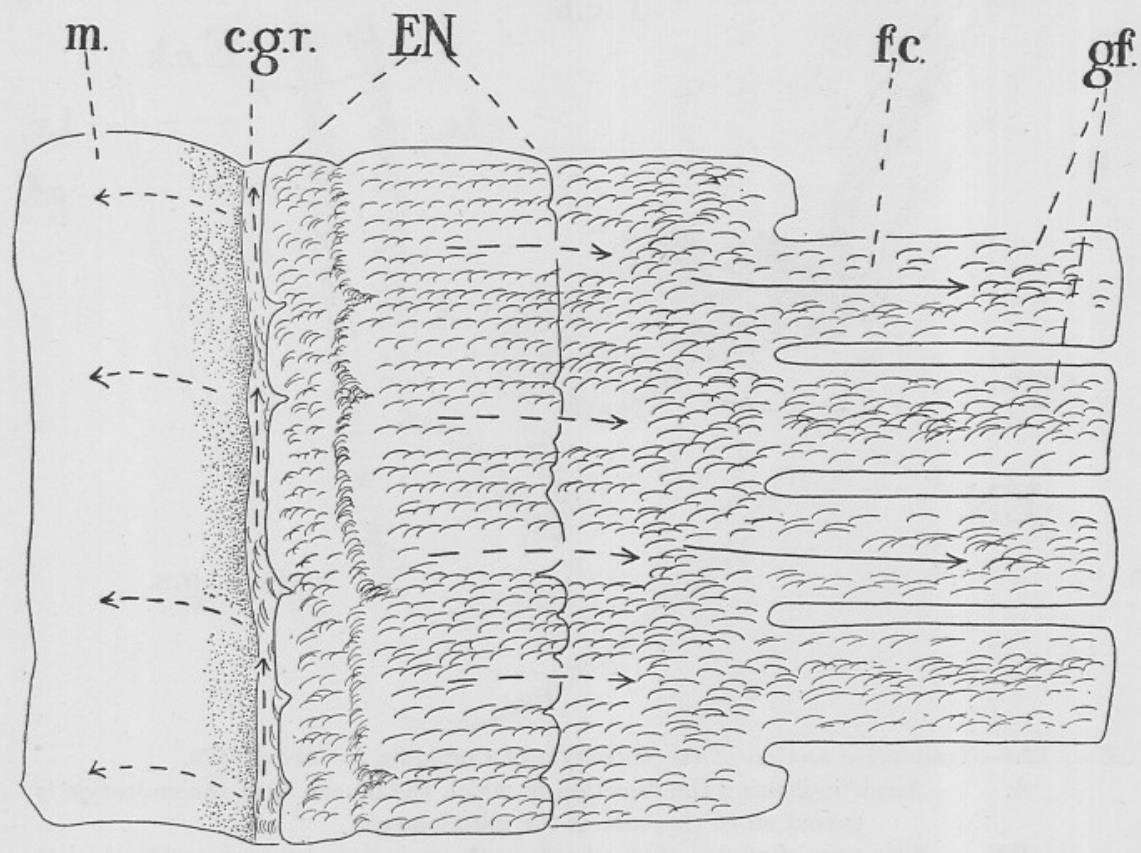

Frg. 11.-View of the endostyle and the bases of four gill-filaments of Crepidula fornicata highly magnified. (Drawn from the living object.)

The dotted arrows on the endostyle, EN, and the complete ones on the bases of the gill-filaments indicate the direction in which mucus is passed from the endostyle on to the bases of the gills. The dotted arrows on the mantle on the floor of the inhalent chamber, $\mathrm{m}$, show the direction in which the cilia in this region lash. Similarly the forward stream in the eiliated groove, c.gr., on the left of the endostyle is indicated by the overlying dotted arrows.

EN. The endostyle consisting of two rows of gland cells between and to the left of which are rows of specially differentiated ciliated cells.

c.gr. Ciliated groove on the left of the endostyle.

g.f. The bases of the gill-filaments.

f.c. Frontal cilia of gill-filaments.

m. The mantle covering the floor of the inhalent chamber.

of the living gill and the surrounding parts shows that the cilia of these glandular cells lash the secreted mucus on to the bases of the gill-filaments, whence it is passed along the face of the gill to be used for the purpose of entrapping food-particles (see Figs. 10 and 11, above), as has already been 
described in this Journal (1, pp. 448, 455). I thought formerly that this mucus was secreted by the epithelium of the gill-filaments (loc.cit.), but there is no doubt now that the greater part is secreted by the glandular cells at the base of the filaments, although it is not unlikely that a certain amount

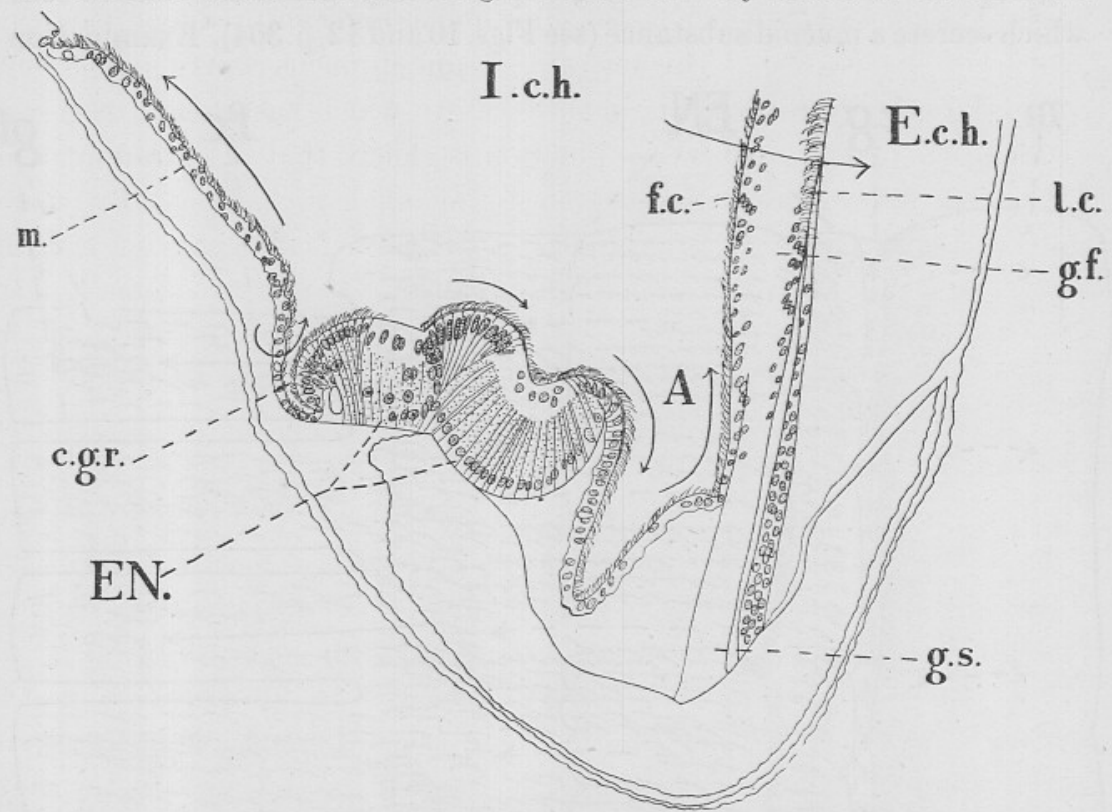

Fig. 12.*-Transverse section of the endostyle of Crepidula ( $\times$ about 105).

A. Arrow indicating the direction in which the mucus from the endostyle is passed on to the base of the gill-filaments.

EN. Two rows of groups of gland cells in the endostyle, between and to the left of which is a group of ciliated cells with apical nuclei.

g.f. Gill-filament.

f.c. Frontal epithelium and frontal cilia on gill-filament.

l.c. Lateral cilia on gill-filament.

g.s. Gill-filament support.

c.gr. Ciliated groove to the left side of the endostyle.

m. Epithelium of mantle the cilia on which lash towards the main foodchannel on the right side of the body as indicated by the arrow placed alongside.

I.ch. Inhalent chamber.

E.ch. Enhalent chamber into which the main current is passed from the inhalent chamber as indicated by the arrow crossing the gillfilament.

of mucus may be secreted by the epithelium of the gill-filaments. These groups of grandular cells may be properly termed an endostyle, since they

* I am indebted to Mrs. Orton for the drawing for this figure as well as those for figures 1,2 , and 8 , and also for assistance with all the other drawings except that for Fig. 3; and also to Mr. E. Ford for kindly lettering Figs. 3, 4, 6, 7, 9 to 12. 
have the same function as the similar groups of glandular cells in a similar position in Amphioxus and Ascidians. The cilia on the endostyle of Crepidula and Calyptræa lash mucus and food-particles on to the gill as has already been stated, but there is also a ciliated groove on the left side of the endostyle which lashes some mucus and captured food-particles forwards (see Fig. 10). This forward stream of mucus contributes largely to the forward stream in the mantle cavity which has already been described (1, p. 448), and whose function is chiefly that of entrapping the coarser food-particles at the entrance to the inhalent chamber. By means of the mucus which is thus carried along this ciliated channel a large proportion of the larger and often innutritious particles become lodged in the food-pouch in the middle of the front portion of the mantle, and are either rejected or eaten by the animal, as has already been observed $(1$, p. 448). In this way and to this extent these animals are able to select their food.

The character of the endostyle of Crepidula may be gathered from the views shown in Figs. 10 and 11, and the transverse section shown in Fig. 12. From the transverse section it is seen that there are two rows of long glandular cells with basal nuclei, and between and to the left of these rows is a line of curious ciliated cells with an apical or distal nucleus. On either side of the endostyle, the epithelium consists of columnar ciliated cells, which become more cubical as they recede from the endostyle. The epithelium on the right side (seen on the left in the section) passes into that of the floor of the mantle cavity. In the latter region the cilia lash away from the endostyle towards the right side of the mantle cavity, and while thus assisting in producing the main current, at the same time help in collecting food-particles into the food-groove on the right side of the floor of the mantle cavity (see Fig. 10, p. 302). The characters of the endostyle and the ciliation of the mantle are the same in Calyptræa as in Crepidula. In Capulus these characters are also the same in the living animal, but sections of the endostyle have not yet been examined.

The remarkable likeness of the endostyle of Crepidula and its allies to that of Amphioxus and Ascidians becomes still more evident when it is compared-as it should be-to a half, the right half, of that of Amphioxus and Ascidians : for it is to be remembered that there is only one half of a ctenidium and only one series of filaments present in Crepidula, whereas both" a right and left series of "filaments" exist in Amphioxus and Ascidians. When, therefore, the endostyle of Crepidula is compared with the right half of that of Amphioxus and Ascidians it will 
be seen that in both there are two rows of similar long glandular cells with basal nuclei, separated by a row of ciliated cells with apical nuclei. The function of the intermediate row of ciliated cells in Amphioxus has been shown to be that of passing on to the gill the mucus formed by the gland cells (see 2, Fig. 3, and p. 25), and the function of the corresponding cells in the endostyle of Crepidula is the same.

It has now been shown (1) that the endostyles in Amphioxus, Ascidians, and Crepidula, and its allies* show a remarkable resemblance, and also that the ciliation and internal supports of the gill-filaments in Gastropods, Lamellibranchs, Amphioxus, Ascidians, and Brachiopods are essentially the same. Consequently it is clear that the homological $\uparrow$ value of any of those characters cannot be great since they are present in widely divergent groups, and indeed would appear to be merely similar adaptations to a similar method of feeding. Therefore it follows that organs present in different animals, but having the same functions, are never necessarily homologous, since practically identical organs are here shown to occur with the same function in groups which are undoubtedly only remotely related. These groups are indeed so remotely related that the characters of the ciliation and internal supports of the gill-filaments, on the one hand, and the endostyle in Crepidula and in the above-mentioned Protochordates, $\ddagger$ on the other hand, must have arisen independently in each case to meet similar requirements. Such plasticity in organisms is indeed remarkable, and its demonstration necessarily increases the difficulties in the already difficult problem of determining what organs in different animals really are genetically related. For instance, the presence of an endostyle in Crepidula confounds all the arguments that we can advance at present in support of the theory that the parabranchial ridges of the Enteroprensta are homologous with the endostyle of Amphioxus (see Willey, 15). These organs may possibly be homologous, but we have no means of determining with any certainty that they really are; and a similar uncertainty must exist in other similar cases.

* It is not improbable that an endostyle may be present also in many other aquatic Gastropods.

$\dagger$ The term Homology is used with the meaning Lankester gives to the term Homogeny (see 16).

¥ It is not contended that the endostyle has arisen independently in Amphioxus and Ascidians, for the well-known reason that development in the latter group indicates a not extremely remote relationship of that group with Amphioxus. 


\section{COMPARISON OF THE ADAPTATIONS IN BRACHIOPODS AND LAMELLIBRANCHS TO THE PROCESS OF FEEDING.}

The general resemblance of the shell and mantle lobe in Brachiopods and Lamellibranchs, as well as the general similarity of their feeding organs, renders a comparison of the adaptations in these groups to the process of feeding a matter of some interest. It has been shown in an earlier work $(1$, p. 463$)$ that it is highly probable that Lamellibranchs have evolved in the direction of perfecting the gill as a feeding organ. In all Brachiopods, so far as is at present known, the feeding organ, the lophophore with its gill-filaments, is in a condition comparable with that of the lower Lamellibranchs, namely, the Protobranchia and the more lowly Filibranchia. No process of fusion of the filaments appears to have taken place in any Brachiopod similar to that generally recognised as having occurred in Lamellibranchs. Since in the latter group this process of fusion appears to have been one of the main factors governing the evolution of that group, the absence of such a process of fusion in Brachiopods may very probably be one of the factors which has resulted in the present decadent condition of that group. Along with the absence of fusion of the gill-filaments in Brachiopods are correlated the absence of fusion of the mantle lobes and the formation of siphons, both of which characters are in many cases of prime importance in the feeding process. Doubtless other disadvantages under which Brachiopods suffer-in comparison with Lamellibranchs in general-are the absence of a locomotory organ in the adult stage represented by the foot in Lamellibranchs, and the sedentary life necessitated in Brachiopods by their structure. These two factors debar Brachiopods from the liberty Lamellibranchs mostly have of moving about, and so being able to place themselves to some extent in a suitable environment. Thus, therefore, probably the sum of these disadvantages may account in some measure for the decadence of the group of Brachiopods, as compared with the flourishing condition of Lamellibranchs at the present day.

It has been shown that the mantle cavity in Brachiopods is physiologically and sometimes morphologically divided into two compartments. This condition is absent in Lamellibranchs, where the mantle cavity in all forms is physiologically entire. It is true that in all Lamellibranchs the mantle cavity is divided either temporarily or permanently into inhalent and exhalent chambers by the gill (see 1), but a corresponding temporary division occurs in both compartments of the Brachiopod shell when the animal is feeding. The nearest approach in Brachiopods to the 
siphonate forms in Lamellibranchs is probably represented by members of those genera in which the postero-lateral angles of the shell are very much drawn out, as in Productus giganteus, Spirifer verneuilli, and species of Leptæna and Platystrophia, and in other forms common in the Rhynchonellidæ, in which the front middle part of the shell is differentiated from the rest in such a way as to resemble a siphon (see Fig. 8, C, p. 296). In all these forms it is highly probable that the shell modifications are correlated with localization of the food-currents. Lingula, however, has been shown by Morse (7) to dispose the mantle setæ in such a way that they form a sort of temporary siphon for the ingoing and the outgoing currents, and this method of forming siphons may occur in other Brachiopods.

From the description of the Brachiopod lophophore given in the preceding pages there can remain no doubt that that organ is analogous to the gill of Lamellibranchs, as has indeed already been observed by Lankester (12). The resemblance in appearance of the lophophore to the palp of a Lamellibranch such as Nucula is indeed close, but that the resemblance is superficial will have been seen from the foregoing account of its function. Hence, if the organs can be compared at all Morse is undoubtedly wrong in comparing the lophophore as he does (13) with the Lamellibranch palp. Thus it is seen that on the whole the parallel developments of organs in the Brachiopods and Lamellibranchs are much fewer than might have been expected from the similarity in their mode of feeding, and the differences which do exist may probably be very largely due to the absence in Brachiopods of that consolidation of the gill-filaments which appears to have played such an important part in the evolution of the Lamellibranchs.

\section{SUMMARY.}

Brachiopods feed in the same way as some Gastropods, as, for example, Crepidula, most Lamellibranchs, Amphioxus, and Ascidians, that is, by establishing a current of water through certain spaces bounded by the body, and sieving off the food-particles contained in that current by means of the lophophore and its cirri.

The cilia on the gill-filaments (cirri) are differentiated in Brachiopods. into lateral and frontal cilia, in essentially the same way and with the same functions as in some Gastropods, most Lamellibranchs, Amphioxus, Balanoglossus, and some Ascidians.

The main current through the mantle cavity in Brachiopods is pro- 
duced chiefly by rows of lateral cilia on the cirri, or gill-filaments, but cilia on the body of the lophophore and on the mantle assist in maintaining this current, which in Crania enters the mantle cavity in the antero-lateral regions of the shell at each side and is expelled in the middle front part of the shell. The mantle cavity in Brachiopods is divided physiologically into two compartments corresponding to the bilateral symmetry of the lophophoral spirals. In some Brachiopods the mantle cavity is also divided morphologically into two compartments, either by medium antero-posterior septa or by actual bifurcation of the whole shell.

Food-collection is effected in Brachiopods mainly by the frontal cilia on the gill-filaments, but tracts of cilia on the filamentar side of the lophophore assist in capturing food-particles. The captured food from both these sources is passed into the well-known food-groove on the lophophore and thence to the mouth.

For the capture of food-particles mucus is secreted on the frontal epithelium of the gill-filaments, at the bases of the gill-filaments, and on the body of the lophophore. A selection of the finer food-particles is effected in Brachiopods to some extent in the lower parts (inhalent chambers) of the mantle cavity ; the heavier undesirable particles being collected on the mantle lobe from which they are expelled from the precincts of the animal.

Some of the characters of the shells of many fossil and recent Brachiopods can be partially explained from the fact of the physiological subdivision of the mantle cavity.

The cephalic gills of Cryptocephalous Polychætes have current-producing lateral cilia and frontal food-collecting cilia essentially similar to those of Brachiopods, Lamellibranchs, and the other groups mentioned above. In Phoronis there is also a similar differentiation of cilia on the lophophoral cilia, but so far as this animal has been examined the functions do not appear to be quite the same as in the other groups examined.

Thus the ciliary mechanisms on the gills of many Gastropods, most Lamellibranchs, Amphioxus, Ascidians, Brachiopods, and the Cryptocephalous Polychætes are essentially similar, and in the three groups to which these animals belong the same mechanism - and similar gill-filament supports-have arisen independently to meet similar or the same requirements, and thus afford an interesting example of parallel evolution.

An endostyle is present at the base of the gill in Crepidula, Calyptræa, and probably also in Capulus. This endostyle of Crepidula shows a remarkable resemblance to that of Amphioxus and Ascidians and 
serves the same purpose, that is, it secretes mucus which is passed on to the gills for the entrapping and the transportation of food-particles. On the right side of the endostyle of Crepidula is a ciliated groove, which carries mucus and some food-particles forwards to serve for catching and expelling the heavier food-particles which enter the front portion of the inhalent chamber.

The independent origin of essentially the same ciliary mechanisms in Molluscs, Protochordata, Brachiopods and some Polychætes, and of a similar glandular organ, the endostyle in Crepidula and Amphioxus and Ascidians, are facts which add greatly to the difficulty of determining with any certainty what are homologous organs in different animals. It also follows that similar organs occurring in different animals and having the same function are never necessarily homologous.

The adaptation in Brachiopods and Lamellibranchs to the process of feeding are compared, and the suggestion is made that the present decadent condition of the former group is due to the absence of that consolidation of the gill and correlated modification of the mantle which appear to have conduced to the present relatively flourishing condition of the Lamellibranchs.

\section{REFERENCES.}

1. J. H. Orton. The Mode of Feeding in Crepidula, with an account of the current-producing mechanism in the mantle cavity, and some remarks on the mode of feeding in Gastropods and Lamellibranchs. Journ. M.B.A. Vol. 9, No. 3. 1912.

2. J. H. Orton. The Ciliary Mechanisms on the Gill and the Mode of Feeding in Amphioxus, Ascidians, and Solenomya togata. Journ. M.B.A. Vol. 10, No. 1. 1913.

3. J. Hérouard. Sur les Courants de Nutrition des Brachiopods. Journ. de Conchyliologie, Paris. 3 Sér., Tome 17. 1877.

4. A. E. Shipley. On the Structure and Development of Argiope. Mittheil. Zool. Sta. Neapel. IV. 1883.

5. A. E. Shipley. Molluses and Brachiopods. Cambridge Nat. Hist. Vol. 3, pp. 463-488. 1895.

6. J. F. Van Bemmelen. Untersuchungen über den Anatomischen und Histologischen Bau der Brachiopoda Testicardinia. Zeit. fur Naturwissenschaft. Jena. XVI, N.F. IX, 1, 2. 1883.

7. E. S. Morse. On Japanese Lingula and Shell Mounds. Amer. Journ. of Science and Arts. Series 3, Vol. 15, p. 157. 1878. 
8. Ph. François. Choses de Nouméa. Arch. de Zool. Exp. et Gén. Sér. 2, Tome 9, p. 233. 1891.

9. W. A. Herdman. Cambridge Nat. Hist. Vol. VII. Fishes and Ascidians, p. 47. 1904.

10. F. Blochmann. Untersuchungen über den Bau der Brachiopoden. Jena. 1892-1900.

11. G. C. Bourne. On the Anatomy and Systematic Position of Incisura (Scissurella) Lytteltonensis. Q.J.M. Sc. Vol. 55, p. 7. 1910.

12. E. Ray Lankester. Ann. \& Mag. of Nat. Hist. Series 4, Vol. XI, p. 93.

13. E. S. Morse. Systematic Position of the Brachiopods. Proc. of Boston Soc. of Nat. Hist. Vol. 15, p. 31. 1873.

14. D. P. Oehlert. Brachiopodes. Manuel de Conchyliologie, by P. Fischer. Paris. 1887. p. 1212.

15. A. Willey. Zoological Results. Part III, p. 324. 1899.

16. E. Ray Lankester. On the Use of the term Homology in Modern Zoology, and the Distinction between Homogenetic and Homoplastic agreements. Ann. \& Mag. Nat. Hist. 4, Vol. 6, p. 34. 1870. 